\title{
VIBRATION ANALYSIS ON ENGINE ELASTOMERIC
}

\author{
ANGULAR MOUNT \\ SUDHEER KUMAR BATTULA ${ }^{1}$, RAMA MURTHY RAJU. $\mathbf{P}^{2}$ \& RATNAM. CH $^{3}$ \\ ${ }^{I}$ Sr. Assistant Professor, Laki Reddy Bali Reddy College of Engineering, Mylavaram Vijayawada Krishna, India \\ ${ }^{2}$ Professor, SRKR Engineering College, Bhimavaram, West Godavari, Andhra Pradesh, India \\ ${ }^{3}$ Professor \& Principal, Andhra University, College of Engineering for Women, Visakhapatnam, India
}

\begin{abstract}
In this paper, the novelty of the work to insist a low cost silently operated and increased operational comfort in naval ships, submarines, automobile ${ }_{2}$ heavy machinery, and other new techniques requires for various applications, to be developed for lowering the noises, shock and vibration isolation. Away of approach is required to reduce the shock; noise and vibration are to urbanize ease vibration isolators that can be utilized to the mount parts that cause vibrations. Active and passive vibration controls methods are used for different types of elastomeric materials were concentrated to create these vibration isolators. In this article, a passive engine angular mount was designed and manufactured and the general issues are discussed with considering to the intend performance as a vibration isolator device. The verdict of this paper projected the new passive engine angular mount design.
\end{abstract}

KEYWORDS: Angular Mount, Isolation, Passive, Shock \& Vibration Analysis

Received: Oct 08, 2018; Accepted: Nov 29, 2018; Published: Dec 31, 2018; Paper Id.: IJMPERDDEC201897

\section{INTRODUCTION}

Rubber is a standout amongst the most widely utilized materials in the design engineering field The fundamental points of interest of rubbers for example high damping flexibility make them winning in a different application like tires, dampers, isolation pads, anti-vibration mounts, gaskets, seals. Alternately, in order to manufacture its individual materials properties, the elastomeric compound which is, for the most part, a blend of rubber, a vulcanization agent, fillers and a few additional ingredients, should be vulcanized to form a predictable rubber-based solid. Amid the vulcanization procedure, the elastic compound is heated up to a temperature at which irreversible response between the rubber molecular chains and the vulcanization agent begins to shape cross-links leads to promoting flexible, three dimensional structures ${ }^{1}$.latest researches and development efforts has been insisted on increasing engine mounting techniques to get enhanced vibration isolation, smooth movement of vehicle, shock, vibration, and noise reduction with fine compressible set and ageing properties ${ }^{2}$. Elastomeric compound development is a major contribution for improvement of engine isolate mounts. So new kind of elastomers that permit specifications of the amount of damping have been developed with the formulation and processing technologies, elastomers can provide specific dynamic properties and to develop the constancy with respect to the varying vehicle environment. So the only elastomeric mount cannot be handled the complicated combination of stiffness and damping, which are important to dynamic behavior to represent the performance of an engine isolate elastomeric mount system. There are various types of engines mounts are available apart from these some of the isolation mounts are much used for better performance for engines in this angular elastomeric mount, 
hydraulic engine mount, electromagnetic mount etc ${ }^{3-10}$. Hydraulic engine mount called fluid filled elastomeric mount, which is a combination of elastomeric mount and viscous dampers were developed, in electromagnetic mount includes active and passive controlled mechanism and also used, designed and developed for aviation. Angular elastomeric mounts is a combination of mild steel angular plates and elastomers sandwiched between these plates and assembled as a single unit and are used in ships, submarines, and heavy rotating machines ${ }^{11-13}$. Even though all these structures, newly urbanized materials follows the developing of vehicles, the elastomers such as rubber and plastic composite materials and elastomeric composite materials will engage the loading position of the engine to isolate elastomeric mount areas ${ }^{14-17}$. Previously various magneto rheological mounts, hydraulic engine mounts, and remaining have been included in section 1 . Till know as per the records no work has been done on engine angular mounts with different types of elastomers. To calculate the potential engine isolate elastomeric angular mount. The results of strain amplitude, temperature induces on these properties also important Elastomers such as natural rubber/polyurethane rubber/Silicone rubber blend system with Isooctane-toluene, styrene, and diviny lbenzene three blended systems and their vibration isolating properties are finded out.

\section{Elastomeric Angular Mount}

An elastomer is a characteristic rubber or any polymer having versatile properties like those of natural rubber. Such materials utilized as a part of isolators because they may be conveniently molded into many desired shapes and selected to provide a wide range of stiffness they have more internal damping than metal springs as they require at least space and weight and they can be bonded to metallic additions adjusted for rearranged connection to the isolated structures Elastomeric isolators are better than different kinds of isolators in that forgiven amount of elasticity, deflection, capacity, energy storage, and dissipation, they require less space and weight, additionally they might be shaped into various designs of a wide range of types and one of the angular mounts shown in figure 1 by and large at a lower cost than different types of isolators of the different elastomers presumably embodies the best combination of mechanical properties for example such as minimum flow, maximum tensile strength, elongation of failure Natural and silicone exhibit superior resistance hydrocarbons and ozone polyurethane being especially attractive for applications including relative high surrounding temperature. Polyurethane is a smart elastic material manufactured for better vibration isolators

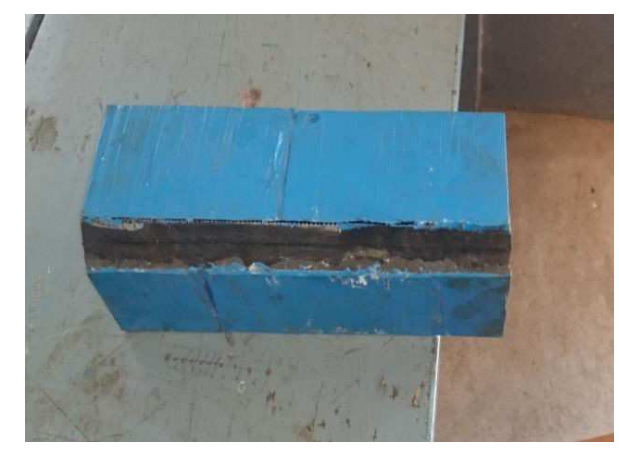

Figure (a): NR Mount

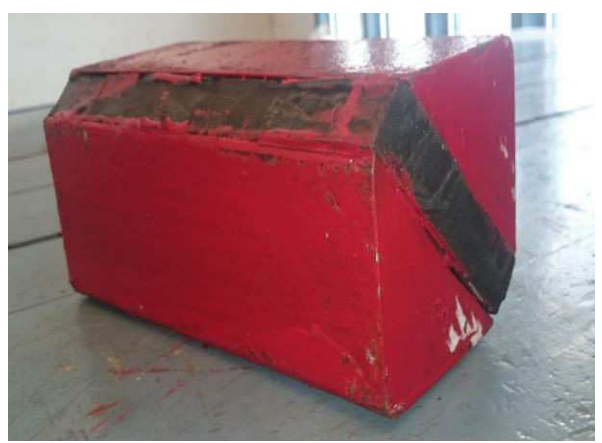

Figure (b): PU Mount 


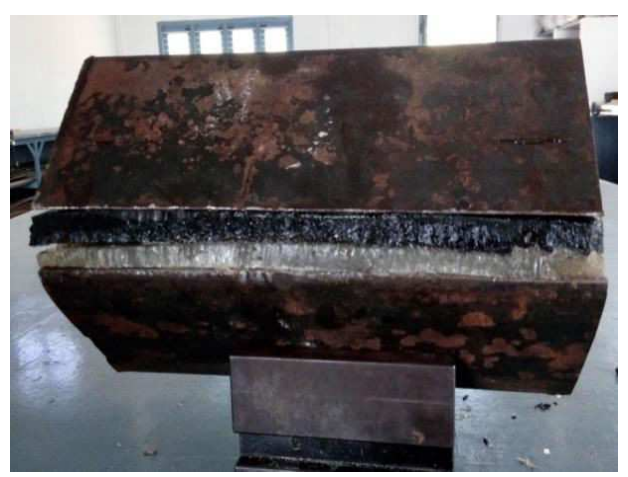

Figure(c) SI Mount

Figure 1: a.b.c. Engine Elastomeric Angular Mounts

\section{MATERIALS AND METHODS}

\section{Materials}

Raw rubber and different chemicals including, stearic corrosive, zinc oxide, n-cyclohexy-2-benzothiazole sulfonamide (CBS), tetra methylthiuram di-sulphide (TMTD), p-jelly, I-resin, MBTS, sulfur, paraffin oil, naphthenic oil, and silicone oil were altogether bought from the rubber industries limited, India. Carbon black was obtained from chemical laboratories research centers ltd Vizag.

\section{Preparation of Rubber Compound Samples}

The compound detailing utilized as a part of the investigation is given in Table 1. The samples for formulations involved polyurethane rubber, natural rubber, silicone rubber and carbon black as the significant segments preparing help and cross-connecting specialist. An option of oils utilized as a part of exacerbating rubbers to keep up a given hardness when an increased level of carbon black and other filler are included. They additionally work as preparing helps and enhance the blending and flow properties. Additives such as, for example, anti-thermal aging agent, anti-oxidant, and petroleum jelly resin were excluded from the formulations. Isotropic Angular Mounts were fabricated according to the strategic methods.

Table 1: Formulation of Rubber Compounds

\begin{tabular}{|l|c|c|c|}
\hline & \multicolumn{3}{c|}{ NR, PU \& SI Compounds } \\
\hline \multicolumn{1}{|c|}{ S No: } & Pu & Nr & Si \\
\hline Millathane Cam & 100 & 100 & 100 \\
\hline Zno & 5 & 5 & 5 \\
\hline Ste-Acid & 2 & 2 & 2 \\
\hline Paraffin Oil & 2 & 3 & 3 \\
\hline Naphthalene Oil & 3 & 2 & 2 \\
\hline Silicone Oil & - & - & 5 \\
\hline C.I Resin & 10 & 15 & 15 \\
\hline Black (Carbon) & 20 & 20 & 18 \\
\hline P-Jelly & 10 & 8 & 8 \\
\hline Sulphur & 2 & 3 & 3 \\
\hline Mbts & 10 & 10 & 12 \\
\hline Tmtd & 1 & 1 & 1 \\
\hline
\end{tabular}

The correlative samples were fabricated to isotropic angular mounts. The curing time at, $150{ }^{\mathrm{O}} \mathrm{C}$ was then determined according to the procedure was described. 
Table 2: Test Results of Rubbers With and Without Aging

\begin{tabular}{|l|c|c|c|c|c|c|c|}
\hline SNO & $\begin{array}{c}\text { Type of } \\
\text { Rubber }\end{array}$ & \multicolumn{2}{|c|}{ Tensile MPa } & \multicolumn{2}{|c|}{ Elongation at Break \% } & $\begin{array}{c}\text { Densityg } \\
/ \mathbf{c m}^{\mathbf{3}}\end{array}$ & $\begin{array}{c}\text { Temperature } \\
\mathbf{O}^{\mathbf{C}}\end{array}$ \\
\hline & & $\begin{array}{l}\text { With } \\
\text { Aging }\end{array}$ & $\begin{array}{l}\text { Without } \\
\text { Aging }\end{array}$ & $\begin{array}{l}\text { With } \\
\text { Aging }\end{array}$ & $\begin{array}{l}\text { Without } \\
\text { Aging }\end{array}$ & & \\
\hline 1 & Polyurethane & 35 & 22 & 700 & 850 & $\begin{array}{c}1.12- \\
1.25\end{array}$ & 120 \\
\hline 2 & Natural Rubber & 24 & 18 & 650 & 760 & $1.03-$ & 1.75 \\
\hline 3 & Silicone & 20 & 17 & 450 & 630 & $1.4-1.55$ & 90 \\
\hline
\end{tabular}

After comparative samples were fabricated the test was performed on a dumb-bell shape according to standards ASTM D638. Test was completed on IND LAB material testing machine and the load was estimated utilizing 10KN load cell and while quasi-static response (displacement) was estimated utilizing extensometer. At first, an elastic example was subjected to 20 load cycles in the strain range of $450 \%$ to get balance out information. For engineering data analysis, it might be more prudent to have exact stress-strain estimations in the range of interest relatively to study the strain at failure. A test was performed at encompassing ambient conditions and strain rate was chosen to $100 \mathrm{~mm} / \mathrm{min}$ and test outcomes were given in Table

\section{EXPERIMENTALWORK}

To acquire the static load-displacement curve of the engine angular mount a set of experimental tests were conducted. These tests were performed in the rubber technology and metallurgy group at the naval science technological laboratory. The machine used was an electromechanical testing machine having 100KN load cell. In these tests, the displacement was controlled variable with an applied displacement speed of $2 \mathrm{~mm} / \mathrm{min}$ to obtain a quasi-static response. The tests were conducted at a room temperature of $25^{\circ} \mathrm{C}$, with the engine angular mount being placed and fixed as shown in figure 2. For the perpendicular loading on three engine, angular mounts tests were performed to determine the behavior of the mount displacement. In the case of the transversal direction, the mount was tested in only one direction due to the mount's geometrical symmetry in this load direction, although three experimental curves were determined corresponding to three different elastomers at the experimental set-up.

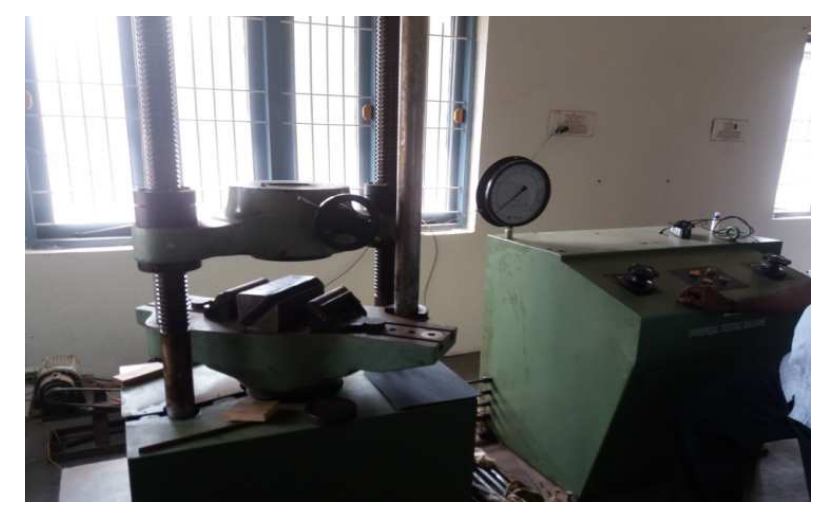

Figure 2: Experimental Set-Up to Obtain the Static Load-Displacement Curves

For each test, the load resulting from the applied displacement was recorded and the results obtained are plotted in the load-displacement curves shown in Figure 3 to Figure 8 


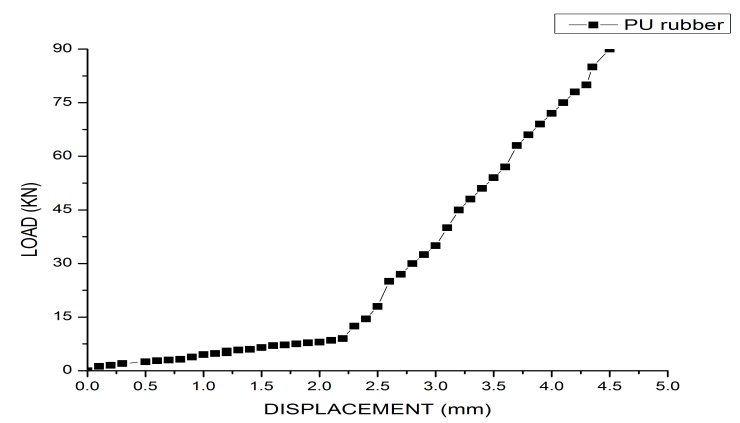

Figure 3: Experimental Load-Displacement Curve for PU Rubber Before Ageing

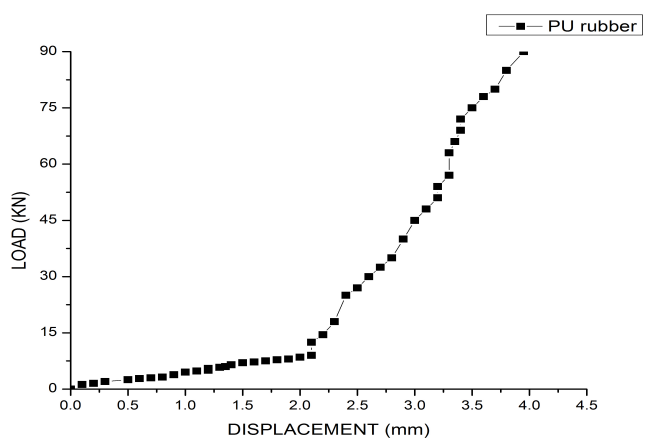

Figure 4: Experimental Load-Displacement Curve for PU Rubber After Ageing

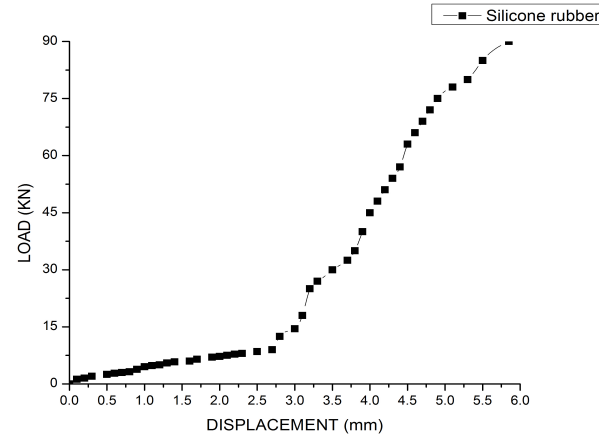

Figure 5: Experimental Load-Displacement Curve for Silicone Rubber Before Ageing

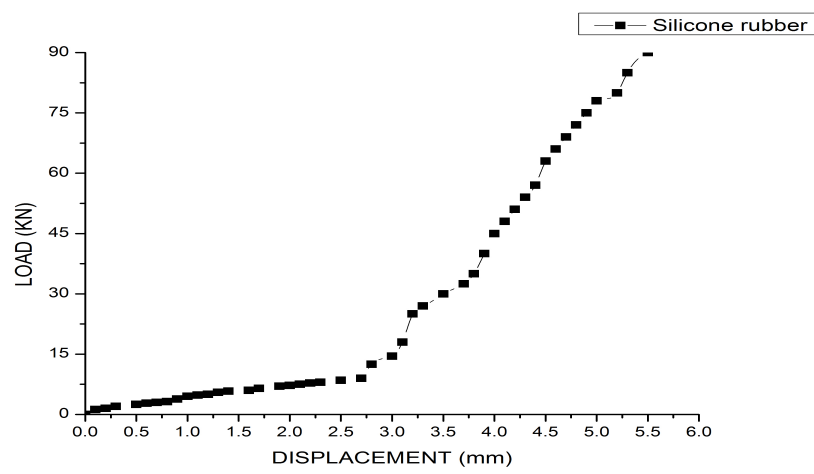

Figure 6: Experimental Load-Displacement Curve for Silicone Rubber After Ageing 


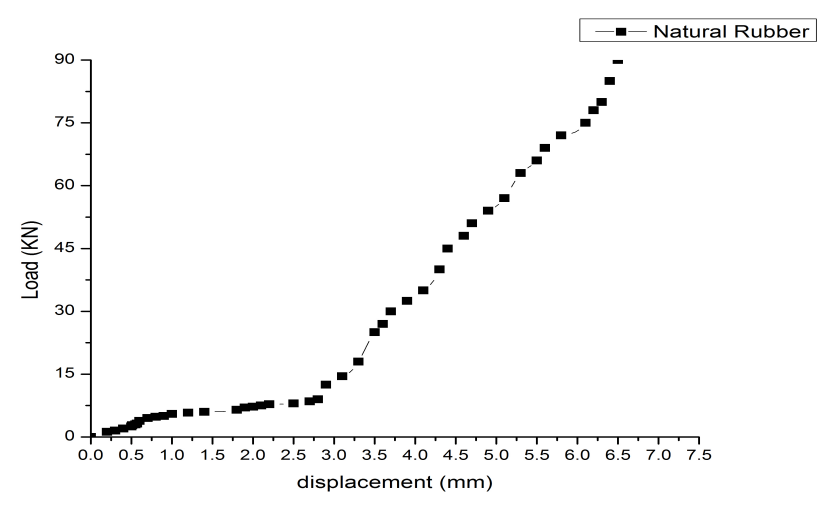

Figure 7: Experimental Load-Displacement Curve for Natural Rubber Before Ageing

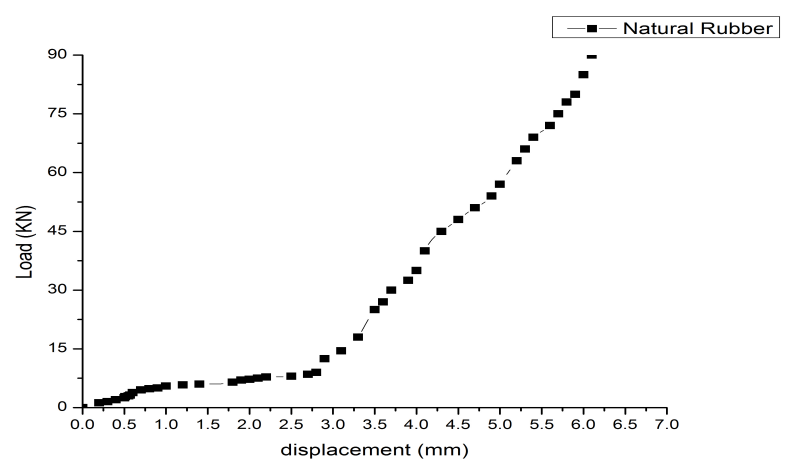

Figure 8: Experimental Load-Displacement Curve for Natural Rubber After Ageing

\section{VIBRATION THEORY}

\section{Undamped Vibration Absorber System}

Here we consider a model of the physical system for the idealization of a primary undamped mechanical system composed of $\mathrm{m}_{1}$ and $\mathrm{k}_{1}$ to which a secondary mechanical system composed of $\mathrm{m}_{2}$ and $\mathrm{k}_{2}$ is attached. The secondary mechanical system is called a vibration absorber. The generalized coordinates $\mathrm{x}_{1}$ and $\mathrm{x}_{2}$ represent the displacements measured from the static equilibrium position of the system.

\section{Single DOF System}

When the secondary system is absent and a harmonic force is applied to $\mathrm{m}_{1}$, the governing equation of motion is that of a single degree of freedom system is given by

$$
\begin{aligned}
& f_{1}(t)=F_{1} \sin \omega t \\
& m_{1} \ddot{x}+k_{1} x_{1}=F_{1} \sin \omega t
\end{aligned}
$$

For harmonically force Single DOF system is given by Eq (2), the resulting forced response is given by equation and with $\zeta=0$ then

$$
x_{s s}(\tau)=\underbrace{\frac{F_{0}}{k}}_{\text {Steadystateamplitude }} H(\Omega) \sin (\Omega \tau-\underbrace{\theta(\Omega))}_{\text {steadystatephase }}
$$




$$
\begin{aligned}
& \text { Where } H(\Omega)=\frac{1}{\sqrt{D(\Omega)}}=\frac{1}{\sqrt{\left.1-\Omega^{2}\right)^{2}+(2 \zeta \Omega)^{2}}} \\
& \theta(\Omega)=\tan ^{-1} \frac{2 \zeta \Omega}{1-\Omega^{2}}
\end{aligned}
$$

It is seen that if excitation frequency is in the vicinity of the natural frequency of the primary system that is when $\Omega=1$ then the resulting response is undesirable. If we are required to operate the system at $\Omega=1\left(\omega=\omega_{n 1}\right)$ or close to it, then a secondary system can be introduced in order to have a finite amplitude at the resonance of the single degree of freedom as illustrated below.

$$
x_{1}(t)=\frac{F_{1}}{k_{1}} \frac{\sin \omega t}{1-\Omega^{2}}
$$

\section{Two DOF System}

The governing equations of the Two DOF System are given by $C_{1}=C_{2}=C 3=K_{3}=f_{2}(t)=0$ thus

$$
\begin{aligned}
& M_{1} \ddot{x}_{1}+\left(C_{1}+C_{2}\right) x_{1}-C_{2} x_{2}+\left(K_{1}+K_{2}\right) x_{1}-K_{2} x_{2}=f_{1}(t) \\
& M_{2} \ddot{x}_{2}+\left(C_{2}+C_{3}\right) x_{2}-C_{2} x_{1}+\left(K_{2}+K_{3}\right) x_{2}-K_{2} x_{1}=f_{2}(t)
\end{aligned}
$$

Here we assume a solution of the form,

$$
\begin{aligned}
& M_{1} \ddot{x}+\left(K_{1}+K_{2}\right) x_{1}-K_{2} x_{2}=F_{1} \sin \omega t \\
& M_{2} \ddot{x}_{2}+K_{2} x_{2}-K_{2} x_{1}=0
\end{aligned}
$$

On and substituting the above following equations we obtain $F_{2}=0$. Then the response amplitudes $\mathrm{X} 1$ and $\mathrm{X} 2$ is obtained, thus the forced response is given by

$$
\begin{aligned}
& X_{1}=\frac{F_{1}}{k_{1}} \frac{\omega_{r}^{2}-\Omega^{2}}{D_{0}} \\
& X_{2}=\frac{F_{1}}{k_{1}} \frac{\omega_{r}^{2}}{D_{0}} \\
& D_{0}=\Omega^{4}-\left[1+\omega_{r}^{2}\left(1+m_{r}\right)\right] \Omega^{2}+\omega_{r}^{2}
\end{aligned}
$$

It is recalled from the equation that $\omega_{r}=\omega_{n 2} / \omega_{n 1}$ is the ratio of the system's uncoupled natural frequency ratio and $\Omega=\omega / \omega_{n 1}$ is the excitation frequency ratio. Since we are forcing the primary system at $\Omega=1$, then $X_{1}=0$, when $\omega_{r}=\Omega=1$, or equivalent that $\omega_{n 1}=\omega_{n 2} \quad \& \omega=\omega_{n 1}$. Evaluating $\mathrm{D}_{0}$ at $\Omega=1$, we find that $D_{0}=-m_{r} \omega_{r}^{2}=-k_{2} / k_{1}$ then the equation leads to $\mathrm{X}_{1}=0$ 
$X_{2}=\frac{F_{1}}{k_{1}} \frac{1}{D_{0}}=\frac{-F_{1}}{k_{1}\left(k_{2} / k_{1}\right)}=\frac{-F_{1}}{k_{2}}$

The harmonic excitation of the primary mass is at a frequency equal to the primary systems natural frequency, the choice of the secondary system's parameters are such that $\omega_{n 1}=\omega_{n 2}$ which makes the response of the primary system zero. If we consider the two degree- of- freedom system from an input energy output perspective all of the energy input to the system at the excitation frequency $\Omega=1$ goes into the secondary system, the absorber system absorbs all of the input energy. The natural frequency of the Two DOF system are given by the roots of $\mathrm{D}_{0}=0$.we find from the equation when $\omega_{\mathrm{r}}=1$, the natural frequencies are solutions of although the presence of absorber is good for the system in terms of attenuating the response of the primary mass at $\omega=\omega_{n 1}$, there are still two resonances given the solution

$$
\Omega^{4}-\left(2+m_{r}\right) \Omega^{2}+1=0
$$

At these two resonances, the system response is unbounded since we have an undamped system.

\section{Selecting the VIBRO-Isolators}

Step 1: If the load is evenly distributed, segregate the total load by the number of mounts and calculate the load on each on the mount.

$$
\text { Load / mount }=\frac{\text { totalloads }}{\text { noofmounts }}=- \text {--.-------- lbs. }
$$

Step 2: Based on the operation speed in cycles per second $(\mathrm{Hz})$, calculate the lowest disturbing frequency $\left(f_{d}\right)$. Change $f_{d}$ over from revolutions per minute (RPM) to cycles every second ( $\left.\mathrm{Hz}\right)$.

Disturbing frequency $\left(\boldsymbol{f}_{d}\right)=\frac{R P M}{60 \mathrm{sec} / \mathrm{min}}-\cdot---H e r t z$.

Step 3: Calculate the natural frequency $\left(\boldsymbol{f}_{n}\right)$ that the system needs for $85 \%$ isolation.

Natural frequency $\left(\boldsymbol{f}_{\boldsymbol{n}}\right)=\frac{f_{d}}{2.45}$

Step 4: To obtain the desired natural frequency $\left(f_{n}\right)$, calculate the required static deflection ( $\left.\boldsymbol{d}_{g}\right)$.Static deflection $\left(\boldsymbol{d}_{s}\right)=\frac{9.8}{\left(f_{n}\right)^{2}}$

Step-5: To acquire the desired natural frequency, calculate the required spring rate $(\mathrm{K})$

Spring rate $(\mathbf{k})=($ load per mount $) /($ static deflection $)$.

Step 6: After that we need to choose the mount and find the deflection (d) using electromechanical testing machine.

Step 7: Calculate the transmissibility after choosing the vibro-isolators based on the actual spring rate for the 
selected mount.

Actual deflection $(\mathrm{d})=$ value of deflection getting on UTM machine.

Actual natural frequency $\left(\boldsymbol{f}_{n}\right)=\sqrt{\frac{9.8}{d}}$

$\operatorname{Transmissibility}(\mathrm{T})=\frac{1}{\left[\frac{f_{d}}{f_{n}}\right]^{2}-1}$

Isolation $(\%)=1-\mathrm{T}$

Table 3: Percentage of Isolation for Elastomeric Angular Mount at Different Engine Rpm

\begin{tabular}{|c|c|c|c|c|}
\hline Sno & RPM & $\begin{array}{c}\text { Isolation (\%) } \\
\text { Pu-Rubber } \\
\text { Mount }\end{array}$ & $\begin{array}{c}\text { Isolation (\%) } \\
\text { Silicone } \\
\text { Rubber } \\
\text { Mount }\end{array}$ & $\begin{array}{c}\text { Isolation (\%) } \\
\text { Natural } \\
\text { Rubber } \\
\text { Mount }\end{array}$ \\
\hline 1 & 2000 & 78.5 & 74.5 & 72.4 \\
\hline 2 & 3000 & 85.3 & 82.5 & 78.8 \\
\hline 3 & 4000 & 89.8 & 84.2 & 83.6 \\
\hline 4 & 5000 & 94.1 & 88.5 & 85.9 \\
5 & 6000 & 96.5 & 92.2 & 90.3 \\
\hline
\end{tabular}

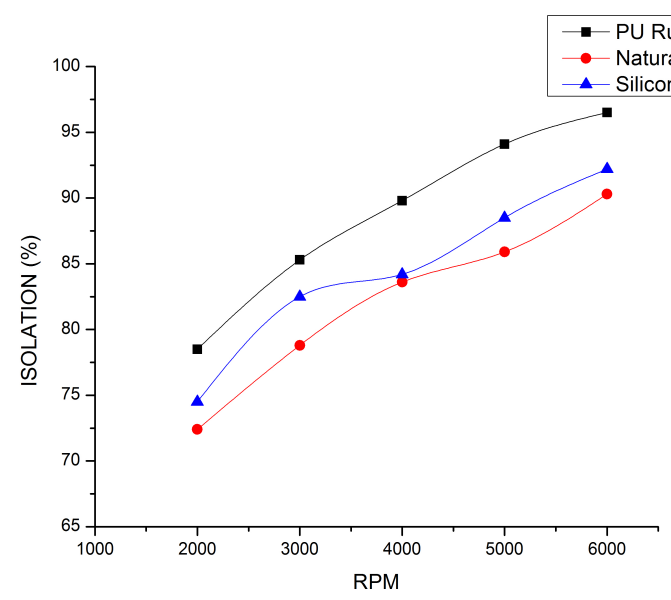

Figure 9: Graph is Computed between RPM versus Isolation for Different Rubbers. The above Table 3 shows the Calculated Result Values Obtained from the Following Eq 16-23, and the Verdict of the Graph Shows that Compare to Silicone and Natural Rubber, Polyurethane Rubber Gives Better Isolation Percentage

Table 4: Correlation between No. of Mounts and Loads Per Mount

\begin{tabular}{|c|c|c|}
\hline Sno & $\begin{array}{c}\text { No.of } \\
\text { Mounts }\end{array}$ & $\begin{array}{c}\text { Load / Mount } \\
\text { (lbs) }\end{array}$ \\
\hline 1 & 2 & 1450 \\
\hline 2 & 4 & 752 \\
\hline 3 & 6 & 473 \\
\hline 4 & 8 & 359 \\
\hline
\end{tabular}

\section{FINITE ELEMENT ANALYSES}

The FE model created and analyzed in this thesis for an elastomeric engine mount has the purpose of being able to 
describe with accuracy its static and dynamic behavior. To do so, one must be able to determine all the properties that influence such behavior. In the case of the static behavior, it" necessary to characterize the constitutive relationship that better describes the behavior of the material used in the mount. The key aspect that sets finite analysis of elastomers angular mounts shown in figure 10-14 (FEA) apart from FEA of metal components is the specification of its material properties. Metals can, generally, be considered as Hookean materials, i.e. materials with a linear stress-strain relationship over its useable stress-strain range. Young's modulus and Poisson's ratio Values for various metals are readily available in the literature and have generally well-known values. In the particular case when the applied loads are sufficient to cause yielding, a non-linear analysis of the metal component can generally be made using a bilinear stress-strain curve or a nonlinear strain hardening rule. In the case of elastomers, each formulation is different, yielding a large spectrum of behaviors, where, generally, there is only a small linear region in the stress-strain curve. Hence, the specification of nonlinear material properties for elastomers is more difficult.

\section{Finite Element Analysis Model}

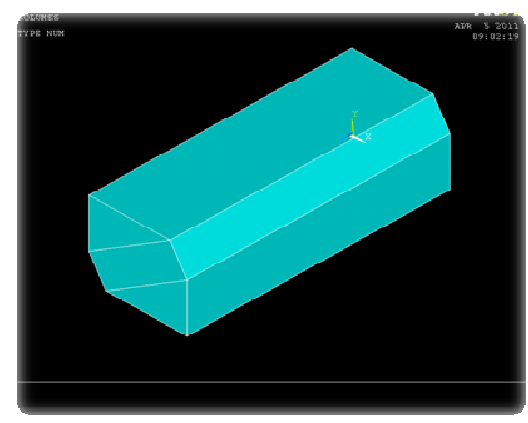

Figure 10: Mount Model

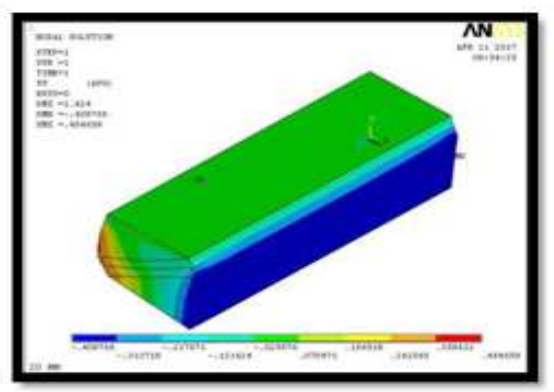

Figure 12: Deflection of Pu Rubber Mount

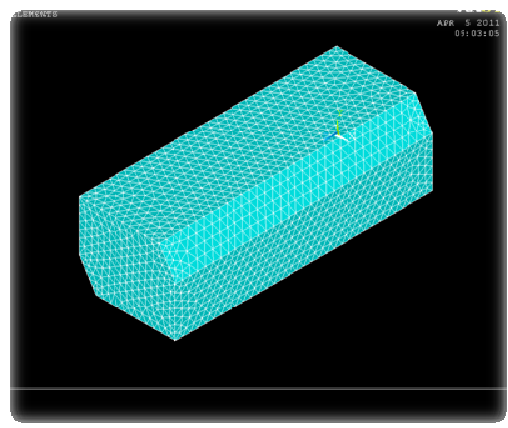

Figure 11: Mesh Model

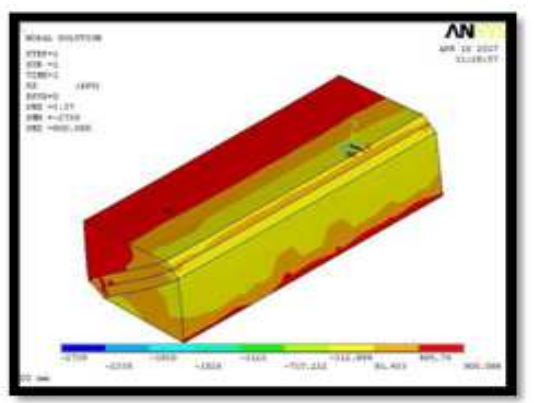

Figure 13: Deflection of Silicone Rubber Mount

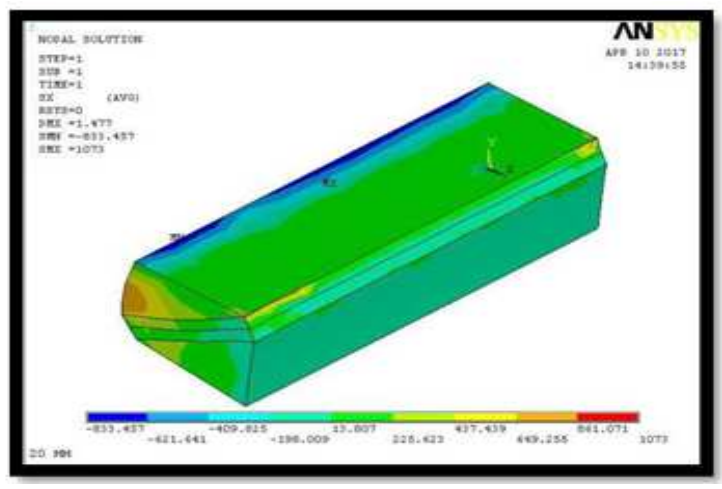

Figure 14: Deflection of Natural Rubber Mount 


\section{Test Results (Static and FEA)}

Table 5: Comparison of Results Between Static and FEA Analysis

\begin{tabular}{|l|l|l|l|l|}
\hline \multicolumn{1}{|c|}{ Before Ageing } & \multicolumn{1}{c|}{ Before Ageing } & \multicolumn{1}{c|}{ After Ageing } & \multicolumn{1}{c|}{ After Ageing } \\
\hline Polyurethane & Static Test (Practical) & $\begin{array}{l}\text { Static Test } \\
\text { (FEA) }\end{array}$ & Static Test (Practical) & $\begin{array}{c}\text { Static Test } \\
\text { (FEA) }\end{array}$ \\
\hline Natural & $\mathrm{d}=6.5 \mathrm{~mm}$ & $\mathrm{~d}=4.34 \mathrm{~mm}$ & $\mathrm{~d}=3.99 \mathrm{~mm}$ & $\mathrm{~d}=4.12 \mathrm{~mm}$ \\
\hline Silicone & $\mathrm{d}=5.85 \mathrm{~mm}$ & $\mathrm{~d}=6.35 \mathrm{~mm}$ & $\mathrm{~d}=6 \mathrm{~mm}$ & $\mathrm{~d}=6.21 \mathrm{~mm}$ \\
\hline
\end{tabular}

\section{RESULTS AND DISCUSSIONS}

A typical rubber formulation consists of at least 10 or more ingredients that are added to upgrade physical properties, influence vulcanization anticipates long term deterioration and enhances process capacity. These ingredients are given in sum amount of aggregate of 100 parts of the rubber (parts per hundred of rubber). An option of oils utilized as a part of aggravating rubbers to keep up a given hardness when the expanded level of carbon black and other filler are included. They likewise work as processing aids and improve the mixing and flow properties. The rubber compound formulation was utilized as a part of the present study is appeared in table1. For engineering data analysis, it might be more appropriate to have exact stress-strain estimations in the scope of premium moderately to contemplate the resist failure. A test was performed at encompassing conditions and strain rate was decided to $100 \mathrm{~mm} / \mathrm{min}$ and test results were given in the table 2. shows that among three different types of rubber polyurethane rubber shown good stress-strain properties compared with natural rubber and silicone rubber.

The beginning consideration of the validity of the different types of rubber angular mounts model was carried out by conducting an experimental test performed in order to obtain the mount's static load-displacement curve are presented and its results are shown in table 4. The quasi-static response shows that polyurethane elastomeric angular gives low displacement compared to remaining rubber angular mounts. In this scenario, three different types of angular mounts were fabricated according to the selection of vibro-isolators step to step-wise process were used to calculate the isolation percentage values and conversion load per mounts listed in table 4 by using the mathematical relations Eq: 16-23, the calculation related values also shown in table 3 . The characteristics of the FE model created to simulate the experimental tests and therefore determine the mount's rubber approximate visco-elastic parameters are mentioned. To conclude, the numerical load-displacement results for three angular mounts i.e., static behavior experimental and FEA presented. The results obtained made possible that the determination of the angular mounts in table 5

\section{CONCLUSIONS}

The novelty of this article computational modeling and simulation of engine angular elastomeric mount was performed to gain an under knowing of the dynamics of naval on board elastomeric angular mounts and to evaluate the effectiveness of current market available solutions. Special consideration was given to the correct modeling of non-linear effects on the static behavior of the mount. The experimental and simulation static analysis of the mounts revealed the presence of distinct region in the load-displacement curve: displacements up to 4.5 and 3.99 mm for PU angular mount, displacements up to 6.4 and $6 \mathrm{~mm}$ for Natural rubber angular mount, displacements up to 5.85 and $5 \mathrm{~mm}$ for Natural rubber angular mount respectively in which the mount had almost constant stiffness and another where the existence of contact between surfaces used an abrupt increased in the mount's stiffness. However, the analyses proved that the mount is 
well developed since its task to isolate, from the ship body engine induced vibrations is successfully performed.

\section{REFERENCES}

1. Jaunich, M, Stark, W, Hoster B. Polym. Test.28, 84. 2009

2. N. Vahdati, and L.K.L. Saunders) “High frequency testing of rubber mounts," ISA transaction, vol. 41, June 2002 pp. $145-154$

3. Y.H. Chen, H.L. Wang, E.D. Su, C.L. Chen, and K.X. Li “Design Method of Aero engine Rubber Vibration Isolator," Science Technology and Engineering, vol.13, July 2013. pp. 5889-5893.

4. A.A. Rashid, and S.R. Yahiya, "Mechanical and ageing properties of hybrid carbon black filled natural rubber composites for engine mount application," 6th Asian-Australasian Conference on Composite Materials: Progress of Composites 2008 in Asia and Australasia, ACCM2008, September 2008, pp. 300-303.

5. M.J.M. Gomes, and A.S. Pouzada, “Dynamic behavior of rubber compounds for engine mounts,” Key Engineering Materials, vol. 230-232, October 2002 pp. 303 - 306.

6. Peter, S. E., Raglend, I. J., \& Simon, S. P. (2014). An architectural frame work of ANN based short term electricity price forecast engine for indian energy exchange using similar day approach. IMPACT Int J Res Eng Technol, 2(4), 111-122.

7. P. Ghosh, R. Stocek, M. Gehde, R. Mukhopadhyay, and R.Krishnakumar, "Investigation of fatigue crack growth characteristics ofNR/BR blend based tyre tread compounds," International Journal of Fracture, vol. 188 , April 2014. pp. 9-21.

8. A.F.M.S. Amin, A. Lion, and P. Höfer, "Temperature history effects in rubber: literature review and critical experiments," vol. 90, April 2010 pp. $347-369$.

9. A. Ueda, T. Ohyama, H. Watanabe, and A. Yoshioka, "Vibration isolation characteristics of chemically modified solution-polymerized rubbers for engine mount use,” Journal of Applied Polymer Science, vol.44, March 1989. pp. 229 - 241.

10. H.T. Chiu, T.C. Cheng, M.C. Yang, and W.G. Hwang, “Anti vibration and Vibration Isolation of ENR/CR Blends,” Advances in Polymer Technology, vol. 17, June 1998, pp. 329-338.

A. Li, and H.D. Liu, "About ant vibration and ant vibration rubber, "World Rubber Industry, vol. 39, February 2012: pp. 6-11.

11. Litvinov, A. N., \& Hadi, A. S. (2015). Study the Effect of Vibration on the Micro-Assemblies for Instrument Devices.

12. J.F. Yang, X.R. Zhou, and W. Ding “Analysis of Oil-retarding Property of Damping Rubber,” Noise and Vibration Control, vol. 33, August 2013, pp. 50-58.

13. S. Opera, "Structure and Properties of Cross-Linked Polyurethane Copolymers," Advances in Polymer Technology, vol.28, August 2009 pp. 165-172.

14. D. Ratna, N.R. Manoj, L. Chandrasekhar, and B.C. Chakra borty "Novel epoxy compositions for vibration damping applications, " Polymers for Advanced Technologies, vol. 15, August 2004 pp. 583-586.

15. H.T. Chiu, J.H. Wu, and Z.J. Shong, "Dynamic Properties of Rubber Vibration Isolators and Anti vibration Performance of Nan clay-Modified PU/PEL Blends System," Polymer Engineering and Science, vol. 45, April 2005 pp. 539-548.

16. Jadhao, V. B., \& Ingole, S. B. (2015). Vibration analysis of three parameter model of adhesively bonded joints. International Journal of Mechanical and Production Engineering Research and Development, 5(1), 61-72.

17. J.H. Wu, C.H. Li, H.T. Chiu, and Z.J. Shong, "Dynamic Properties of Rubber Vibration Isolators and Anti vibration Performance of Ethylene-Propylene-Diene Monomer/Nylon 6 Blend Systems, ” Journal of Applied Polymer Science, vol. 108, 
March 2008 pp. 4114-4121.

18. Sudheer Kumar. battula, Lanka Ramesh Preventing Shock and Vibrations Using Angular Mount with Polyurethane Elastomer" International Journal of Statistika and Mathematika, ISSN: 2277- 2790 E-ISSN: 2249-8605, Volume 3, Issue 2, 2012 рp 34-41

19. M.Z.Sariman, M.Hafiz Harun, A.K.Mat Yamin, F.Ahmad, and M.R Yunos, Magneto rheological Fluid Engine Mounts: A Review on Structure Design of Semi Active Engine Mounting," International Journal of Materials Volume 2, 2015 
